\title{
Malignant lymphoma with a high content of epithelioid histiocytes
}

\author{
DOROTHY HAYES AND J. H. ROBERTSON
}

From the Department of Histopathology, Belfast City Hospital, Belfast, Northern Ireland, UK

SUMMARY A series of 12 patients with a rare malignant lymphoma containing numerous epithelioid histiocytes (MLEH), originally believed to be an atypical variant of Hodgkin's disease, is described. Clinicopathological studies suggest MLEH is a distinct entity among the non-Hodgkin's lymphomas which is generally resistant to therapy and has an unfavourable prognosis. Differentiation of the disease from angioimmunoblastic lymphadenopathy and Hodgkin's disease is discussed. In the necropsy case MLEH had transformed into a malignant lymphoma of histiocytic type.

A rare type of lymphoma with a high content of epithelioid histiocytes was described by Lennert and Mestdagh in 1968 and considered to be an atypical variant of Hodgkin's disease. Subsequently the lesion was redesignated 'lympho-epithelioid cellular lymphoma' (Lennert et al., 1975) and uncertainty as to its exact nature was expressed. It now seems that the disease originally described was not a single entity but included several different types of lymphoma (Tindle and Long, 1977).

The clinical and pathological findings of malignant lymphoma with a high content of epithelioid histiocytes (MLEH) were described by Burke and Butler (1976) and Kim et al. (1978) in two series of patients in an attempt to define the disease more exactly. They suggested that MLEH, or 'Lennert's lymphoma' as the lesion is sometimes termed, is a distinct form of malignant lymphoma that may be distinguished from other neoplastic diseases of lymph nodes. These papers have stimulated an increased awareness of MLEH, but its exact nature and relationship to other forms of lymphoma remain uncertain, and clarification requires the study of further cases. We present a series of 12 cases of MLEH diagnosed on morphological criteria according to Kim et al. (1978) and attempt to determine whether the condition is an entity distinct from other forms of lymphoma.

\section{Material and methods}

This study is based on a series of 12 patients whose pretreatment lymph nodes were available in the files in the histopathology department of the Belfast City

Received for publication 2 January 1979
Hospital from 1954 to 1978 . In a review of 350 cases diagnosed as Hodgkin's disease, 33 lymph nodes were identified with a high content of epithelioid histiocytes. Twenty-one cases were confirmed as Hodgkin's disease, 13 lymphocyte predominant and eight mixed cellularity in type. Twelve lymph nodes were found containing many epithelioid histiocytes but lacking the necessary features for a definite diagnosis of Hodgkin's disease. Necropsy material was available from one patient. These cases form the basis of this study.

The following morphological criteria were considered essential for diagnosis of MLEH: replacement of the normal lymph node architecture, a diffuse proliferation of epithelioid histiocytes, and a proliferation of lymphoid cells. Lymph nodes containing cells resembling Reed-Sternberg cells, even if sparse, were excluded to avoid confusion with Hodgkin's disease. A prominent arborising vascular pattern, which characterises angioimmunoblastic lymphadenopathy, rendered a lymph node unacceptable.

The clinical findings, course, and laboratory data were compiled retrospectively from the clinical charts and were necessarily incomplete as most patients had been treated before the advent of modern investigative techniques.

\section{Results}

PATHOLOGICAL FINDINGS

In all 12 cases the morphology of the lymph nodes was remarkably uniform. The architecture was almost completely obliterated by a diffuse proliferation of epithelioid histiocytes admixed with lymphoid 
cells, eosinophils, and occusional plasma cells (Fig. 1). The only residual architecture noted in three cases was occasional peripheral non-neoplastic follicles compressed by the surrounding proliferation of histiocytes and lymphoid cells. The epithelioid histiocytes tended to dominate the picture and frequently overshadowed the other cellular components. They had mainly a very diffuse arrangement but also formed poorly defined cell clusters. Sparse Langhans type giant cells were noted in one case. The lymphocytic component consisted of small lymphocytes admixed with scattered larger lymphoid cells or immunoblasts. The small lymphocytes showed only minimal nuclear irregularity. There was no evidence of cleaved follicle centre cells. In one lymph node sparse eosinophilic interstitial PAS-positive material was present. The capsule was always involved with obliteration of the peripheral sinuses, and extranodal invasion to a varying degree was a consistent finding (Fig. 2). In the extranodal fat the infiltrate was sometimes less polymorphous than in the node. Lymphocytes were more numerous, and the epithelioid histiocytes no longer dominated the picture.

\section{Necropsy findings}

A necropsy was performed in case 9. Lymph nodes from multiple sites were enlarged, some were necrotic with areas of acellular hyaline fibrosis relating to therapy, and others were replaced by a lymphoma. The spleen and liver were involved, and the bone marrow showed extensive disease. The disease had transformed into a diffuse malignant lymphoma (Fig. 3) of histiocytic type (Rappaport classification). The epithelioid histiocytes of the pre-treatment surgical material were no longer evident.

\section{CLINICAL FINDINGS}

The clinical findings in the 12 patients are summarised in the Table. Their ages ranged from 45 to 87 years, and there were five men and seven women. All the patients had peripheral lymphadenopathy, which was confined to the cervical region in four and was generalised in eight. Only two patients had evidence of enlarged mediastinal glands on chest $x$-ray, and in only one was the spleen palpable on clinical examination. In no patient was there evidence of involvement of the nasopharyngeal lymphoid tissue. A lymphangiogram was performed in one patient (case 10), the abdominal glands being normal. Systemic symptoms of sweating, pyrexia, or significant weight loss were present in six of the 12 patients at diagnosis.

There were few significant laboratory findings. Anaemia and leucopenia were present in two patients, and a further two had a mild eosinophilia. None had a lymphocytosis. Liver function tests were
Table Age, clinical staging, treatment, and survival of the 12 patients

\begin{tabular}{|c|c|c|c|c|}
\hline Case & Age/Sex & Clinical stage & Treatment & $\begin{array}{l}\text { Survival from } \\
\text { diagnosis } \\
(m t h)\end{array}$ \\
\hline 1 & $52 \mathrm{~F}$ & IA & Radiation & $72 *$ \\
\hline 2 & $87 M$ & IIA & Radiation & 4 \\
\hline 3 & $72 \mathrm{M}$ & IIA & Radiation & 10 \\
\hline 4 & $46 \mathrm{~F}$ & IIIB & $\begin{array}{l}\text { Radiation } \\
\text { Mustine } \\
\text { Cortisone }\end{array}$ & 14 \\
\hline 5 & $63 \mathrm{~F}$ & IIIB & $\begin{array}{l}\text { Mustine } \\
\text { Chlorambucil }\end{array}$ & 4 \\
\hline 6 & $60 M$ & IIIB & $\begin{array}{l}\text { Cyclophosphamide } \\
\text { Prednisone }\end{array}$ & 14 \\
\hline 7 & $76 \mathrm{~F}$ & IIIA & Mustine & 12 \\
\hline 8 & $52 \mathrm{~F}$ & IIIB & $\begin{array}{l}\text { Radiation } \\
\text { Prednisone }\end{array}$ & 21 \\
\hline 9 & $66 \mathrm{~F}$ & IIIB & $\begin{array}{l}\text { Radiation } \\
\text { Prednisone }\end{array}$ & 29 \\
\hline 10 & $65 \mathrm{M}$ & IA & Radiation & $7 *$ \\
\hline 11 & $45 M$ & IIIA & $\begin{array}{l}\text { Cyclophosphamide } \\
\text { Vinblastine } \\
\text { Procarbazine } \\
\text { Prednisone }\end{array}$ & $4^{*}$ \\
\hline 12 & $67 \mathrm{~F}$ & IIIB & Prednisone & 4 \\
\hline
\end{tabular}

*Alive.

normal apart from two instances of an increased alkaline phosphatase. Seven patients had an estimation of their serum proteins with electrophoresis, and two showed a mild polyclonal hyperglobulinaemia.

As most of these patients were seen before the introduction of the newer methods of assessment of lymphoma, the clinical stages shown in the Table are without the benefit of a lymphangiogram (except case 10) or laparotomy. Nevertheless, from the generalised nature of the lymphadenopathy it was clear that eight of the 12 patients had disseminated disease. Of these eight patients, seven have died with a survival time ranging from four to 29 months. None obtained even a temporary complete response to treatment, although their chemotherapy was less intensive than is the current practice. The eighth patient with generalised disease is currently receiving combination chemotherapy but has not yet achieved a complete remission after four months of treatment. Of the four patients with apparent stage I or II disease, one (case 1), who was treated by irradiation, is a long-term survivor, being alive and well six years later. Two others survived only four and 10 months, and the fourth patient has survived for seven months but is in incomplete remission following radiotherapy.

\section{Discussion}

Proliferation of epithelioid histiocytes is a feature common to several types of lymphoma and is often a source of diagnostic confusion. It is now realised 


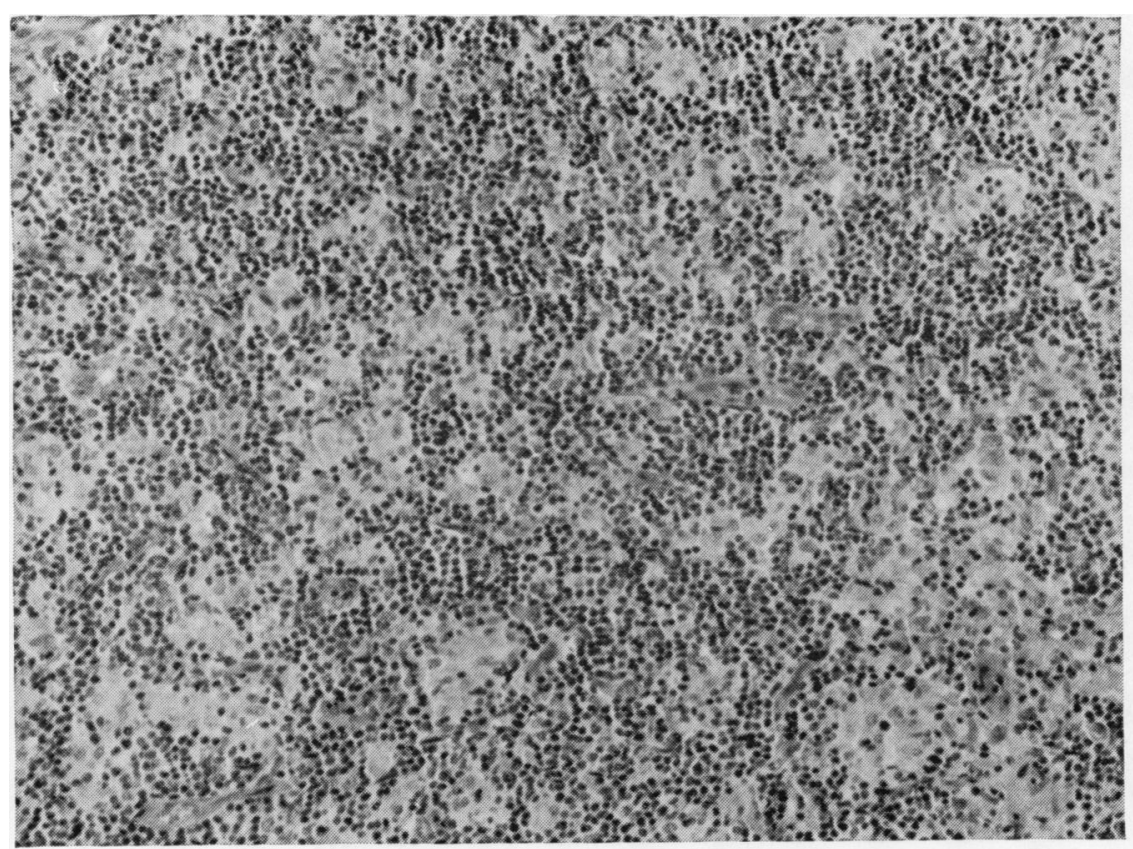

(a)

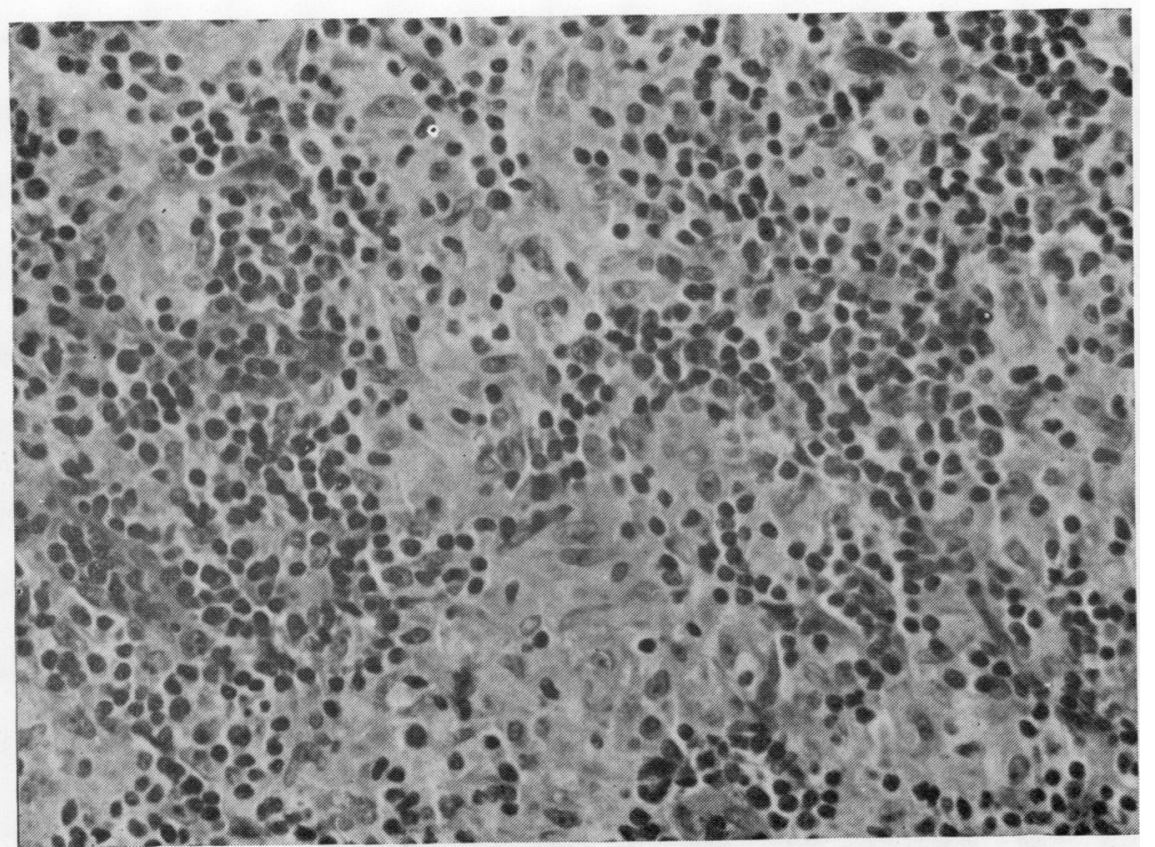

(b)
Fig. 1 Lymph node showing effacement of architecture by a diffuse proliferation of lymphocytes and histiocytes.

(a) Haematoxylin and eosin $\times 160$; (b) $H$ and $E \times 312$. 


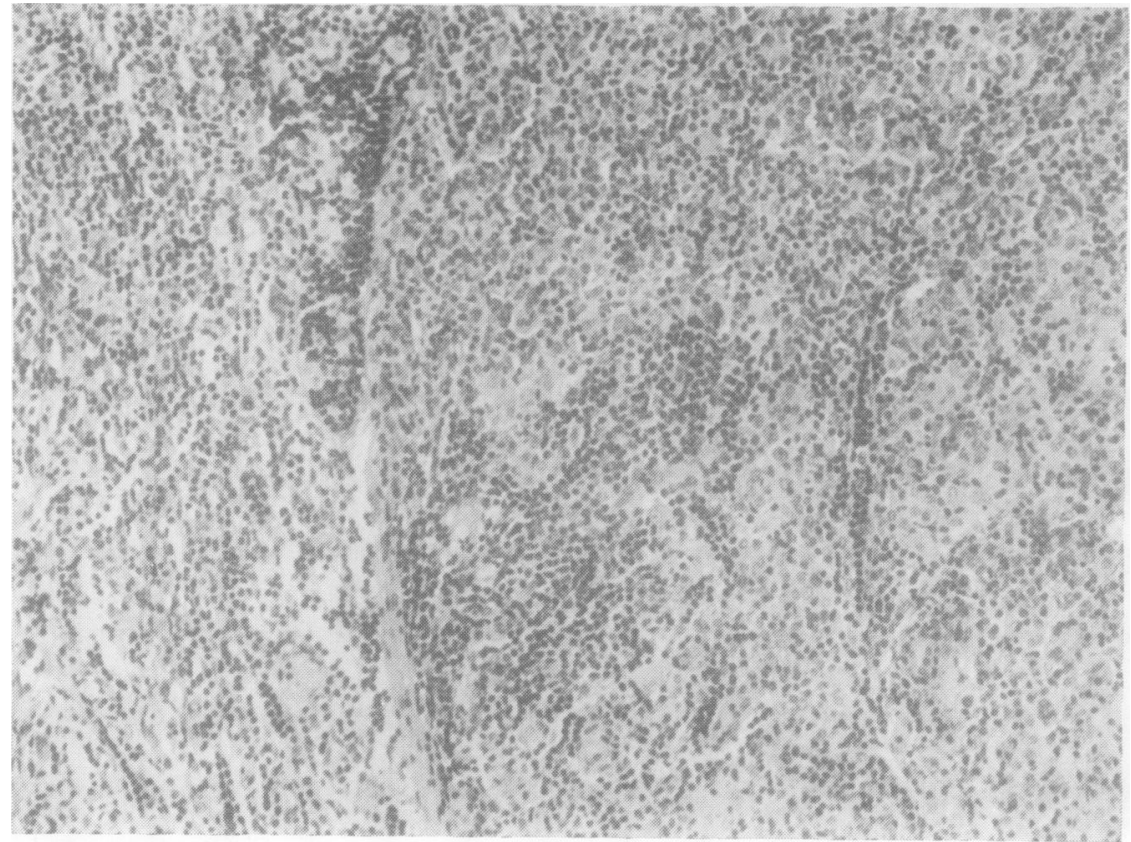

Fig. 2 Lymph node showing capsular and extranodal involvement. $H$ and $E \times 160$.

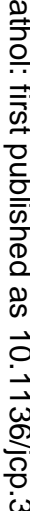

ר

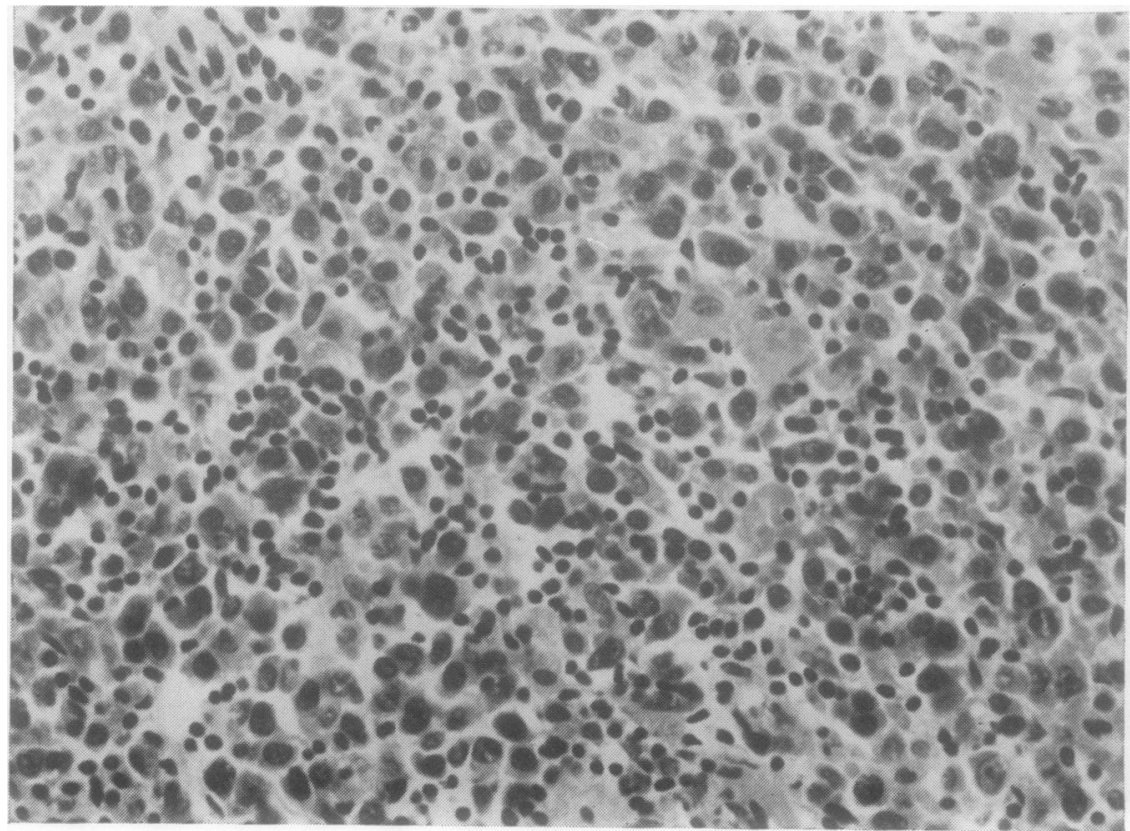

Fig. 3 Necropsy

lymph node.

Transformation of $M L E H$ into diffuse lymphoma of histiocytic type. Epithelioid histiocytes are absent. $H$ and $E \times 312$. 
that the lymph nodes with numerous histiocytes originally described by Lennert and Mestdagh (1968) were not homogenous and included more than one form of lymphoma.

This paper describes 12 cases of MLEH originally classified as an atypical variant of Hodgkin's disease. It was only when recent publications (Burke and Butler, 1976; Kim et al., 1978) drew attention to MLEH as a possible entity that we recognised the remarkably uniform morphology of this lesion in the lymph nodes. The major histological features were the same as those described by Kim et al. (1978), apart from the marked degree of nuclear irregularity in the lymphoid cells, which we did not confirm. These two series included patients who underwent staging laparotomy (Burke and Butler, 1976; Kim et al., 1978). In both, the morphology of the spleen, liver, and lymph nodes reproduced that of the diagnostic pre-treatment peripheral lymph node and included numerous epithelioid histiocytes. None of our cases had a staging laparotomy. One case (No. 9) came to necropsy, and involvement of the lymph nodes, liver, spleen, and bone marrow by a lymphoma was confirmed. The disease had transformed into a diffuse lymphoma of histiocytic type and epithelioid histiocytes were no longer evident. Evolution of MLEH into a diffuse lymphoma has previously been documented (Klein et al., 1977; Kim et al., 1978; MacGillivray and Macintosh, 1978) and suggests that the disease is not an atypical variant of Hodgkin's disease and should be classified among the non-Hodgkin's lymphomas.

From its histological features no difficulty was found in separating MLEH from inflammatory and reactive conditions in lymphoid tissue. Toxoplasmosis, sarcoidosis, and tuberculosis bear only a superficial histological resemblance and do not efface the architecture of the lymph nodes. Diagnostic problems are much more likely to arise with the recently established entity of angioimmunoblastic lymphadenopathy (Frizzera et al., 1975; Lukes and Tindle, 1975) and Hodgkin's disease, with important differences in prognosis and treatment. In angioimmunoblastic lymphadenopathy almost $50 \%$ of lymph nodes show a similar marked proliferation of epithelioid histiocytes, but this is accompanied by a very characteristic arborising pattern of blood vessels. A consistent polyclonal hyperglobulinaemia is present and sometimes a Coombs' positive haemolytic anaemia. In none of the lymph nodes in this series was there a prominent vascular pattern, and there were no characteristic laboratory findings, a mild hyperglobulinaemia being found in only two of seven patients investigated. While there are certain clinical similarities, correlation of the laboratory findings with the lymph node morphology separates the two diseases without difficulty.

Our experience reflects the diagnostic confusion that has arisen between MLEH and Hodgkin's disease (Lennert and Mestdagh, 1968). The 12 cases studied were selected on the basis of morphology and have in common with the lymphocytic and histiocytic type of Hodgkin's disease, and sometimes the mixed cellularity type, numerous epithelioid histiocytes. We agree with Kim et al. (1978) that MLEH differs markedly from the mixed cellularity type of Hodgkin's disease, where numerous Reed-Sternberg cells and mononuclear Hodgkin's cells are a major diagnostic feature. Lymphocytic predominant Hodgkin's disease with a diffuse lymphocytic and histiocytic pattern presented us with the major diagnostic problem. In this variant Reed-Sternberg cells and their polyploid variant may be extremely sparse and the morphology then closely resembled MLEH. A useful feature in differentiation was the consistent capsular involvement with frequent invasion of extranodal tissues. This is rarely seen in lymphocyte predominant Hodgkin's disease. We did not find nuclear atypia or irregularity in the lymphocytic cells to be marked in MLEH, but immunoblastic differentiation with the development of large lymphoid cells was helpful in diagnosis. Despite these differences it is our view that in an occasional case morphological separation of the diffuse lymphocytic and histiocytic type of Hodgkin's disease from MLEH may be almost impossible. When the clinical findings and course were studied it became clear that the outlook differed markedly in the two diseases. In lymphocyte predominant Hodgkin's disease (Lukes et al., 1966; Thomas and Berard, 1973) the disease had a relatively early onset and survival figures were good, even at a time when clinical investigation was less thorough and therapy less intensive. In contrast, our youngest patient was 45 years of age and most were middle-aged or elderly. No less than eight of the 12 patients had widespread disease at presentation, and response to treatment was poor and survival short. However, our series does not give so clear an indication of the prognosis of localised disease in MLEH. Of four patients, one (case 1) has survived more than six years and is in complete remission, and a further patient (case 10) is in incomplete remission seven months after presentation. The remaining two patients are dead, but as staging procedures were limited at the time of diagnosis more extensive undetected disease may well have been present. We consider from this series that MLEH is an entity that may generally be distinguished from other lymphomas by its morphological features and should be classified within the non-Hodgkin's lymphomas. Clinically, it is a disease that is frequently disseminated at diagnosis, is more resistant to therapy 
than Hodgkin's disease, and has a poor prognosis.

The consultant radiotherapists, Northern Ireland Radiotherapy Service, kindly permitted access to their records, and this is gratefully acknowledged. We thank Miss R. Fox for typing the manuscript and Mr J. Orchin for technical and photographic assistance.

\section{References}

Burke, J. S., and Butler, J. J. (1976). Malignant lymphoma with a high content of epithelioid histiocytes (Lennert's lymphoma). American Journal of Clinical Pathology, 66, 1-9.

Frizzera, G., Moran, E. M., and Rappaport, H. (1975). Angio-immunoblastic lymphadenopathy. American Journal of Medicine, 59, 803-818.

Kim, H., Jacobs, C., Warnke, R. A., and Dorfman, R. F. (1978). Malignant lymphoma with a high content of epithelioid histiocytes. Cancer, 41, 620-635.

Klein, M. A., Jaffe, R., and Neiman, R. S. (1977). "Lennert's lymphoma" with transformation to malignant lymphoma, histiocytic type (immunoblastic sarcoma). American Journal of Clinical Pathology, 68, 601-605.

Lennert, K., and Mestdagh, J. (1968). Lymphogranulomatosen mit konstant hohem Epithelioidzellgehalt.
Virchows Archiv Abt. A Pathologische Anatomie, 344, 1-20.

Lennert, K., Mohri, N., Stein, H., and Kaiserling, E. (1975). The histopathology of malignant lymphoma. British Journal of Haematology, 31, Supplement, 193-203.

Lukes, R. J., Butler, J. J., and Hicks, E. B. (1966). Natural history of Hodgkin's disease as related to its pathologic picture. Cancer, 19, 317-344.

Lukes, R. J., and Tindle, B. H. (1975). Immunoblastic lymphadenopathy. A hyperimmune entity resembling Hodgkin's disease. New England Journal of Medicine, 292, 1-8.

MacGillivray, J. B., and Macintosh, W. G. (1978). A case of Lennert's lymphoma. Journal of Clinical Pathology, 31, 560-566.

Thomas, L. B., and Berard, C. W. (1973). Hodgkin's disease: relationship of histopathological type at diagnosis of clinical parameters and to histological progression and anatomical distribution at autopsy. GANN Monographs on Cancer Research, 15, 253-273.

Tindle, B. H., and Long, J. C. (1977). Fever, lymphadenopathy and splenomegaly in a 60-year-old woman. (Massachusetts General Hospital, Case record 30-1977) New England Journal of Medicine, 297, 206-211.

Requests for reprints to: Dr Dorothy Hayes, Department of Histopathology, The Laboratories, Belfast City Hospital, Belfast BT9 7AD, Northern Ireland. 